\title{
OZONE THERAPY MAY BE AN ALTERNATIVE METHOD FOR THE TREATMENT OF CUTANEOUS LEISHMANIASIS: CASE REPORTS
}

\author{
RUBA KELLO ${ }^{1}$, MOHAMED MUHANAD BADAWI ${ }^{2}$ \\ 1,2 Ozone Supportive Therapy Clinic, Aleppo, Syria.
}

Objective:In the context of the Syrian crisis the cutaneous leishmaniasis form caused by L. tropical is the most important in terms of risk of being introduced in neighboring countries. It also presents more treatment failures (up to $20 \%$ of cases may become chronic) [1]. So, more work needs to be done in this areato find an alternative treatment which is both low in cost and easy to administer.This research focuses on two cases in Aleppo with cutaneous Leishmaniasis (CL), different for sex and age, it shows the effectiveness of oxygen-ozone therapy by using"bagging modality of ozone administration".So it is appropriate to evaluate this therapy in further clinical studies with a greater number of patients.

Keywords: Cutaneous Leishmaniasis, Ozone Therapy,L. tropica.

\section{Corresponding Author: Ruba Kello}

E- mail: r-k-pharmacist@live.co.uk

Kelloruba@gmail.com

Tel: (+)963944728412

\section{INTRODUCTION}

Cutaneous leishmaniasis (CL) is a worldwide disease caused by an infection with the protozoan parasite Leishmania transmitted via sand flies. It is endemic in many of the poorest countries of all continents. "Aleppo boil" is one of the recognised names given to this disease in the medical literature [2]. Old World cutaneous leishmaniasis is one of the most prevalent insect-borne diseases within the World Health Organization's Eastern Mediterranean Region [3]. Zoonotic cutaneous leishmaniasis is caused by the protozoan parasite Leishmania major, which is transmitted through the infectious bite of the female Phlebotomus papatasi sand fly; the animal reservoirs are the rodent genera Rhombomys, Psammomys, and Meriones. Anthroponotic cutaneous leishmaniasis is caused by L. tropica and transmitted between humans by the Ph. sergenti sand fly [2].

In the north of Syria, in Aleppo and its surroundings, CL is of an anthroponotic type and is due to L. tropica ZMON-76 [4]. In the suburbs of the capital Damascus, zoonotic CL is due to L. major ZMON-26 [5]. Moreover, L. infantum has also been suggested as the causative agent in the Syrian Mediterranean area [6,7].The relationship between war and emergence of infectious diseases, including leishmaniasis, is well known throughout the history of medicine and has been the subject of extensive literature research $[8,9]$.

One study provided the first quantitative evidence of the epidemiological evolution of CL in Syria during the war where thedata on number of CL cases for the period 2011-2018 were extracted from three different surveillance systems: The Ministry of Health $(\mathrm{MoH})$ routine surveillance system, the MOH/WHO sentinel-syndromic Early Warning Alert and Response System (EWARS), and surveillance data collected by the international nongovernmental organization (NGO) the MENTOR Initiative. The analysis of data from the three available 
sources over the period considered indicates that number of reported cases progressively grew from prewar levels to reach a peak in 2015, decreased in 2016, remained stable in 2017, and increased again in 2018. Such a trend was mirrored by changes in incidence of infection. Some governorates, which used to report low numbers of CL cases, started recording higher number of cases after the onset of the war [10].

Glucantime remains the first-line treatment for cutaneous leishmaniasis [11].Resistance to Glucantime is an important issue because there are few other drugs available for the treatment of cutaneous leishmaniasis [12]. However, concerns about the resistance of parasites to Glucantime have appeared [13]. So, more work needs to be done in this area to find an alternative treatment which is both low in cost and easy to administer.

ozone therapy has often been tried in medical science and has become more popular due to its antimicrobial, biocompatibility and healing properties.

This research focuses on three cases in Aleppo with cutaneous Leishmaniasis (CL), different for sex and age, it shows the effectiveness of oxygen-ozone therapy by using two different modalities of ozone administration.

\section{CASE REPORTS}

Prior informed consent was taken from all patients before the study.Patients were diagnosed using a direct smear test in addition to clinical diagnosis.Detailed personal information was obtained from each patient, including the type, number, size, duration, and location of lesion(s), date of onset, age of patient at time of onset, earlier treatments received, and period of healing (if any). The lesions were photographed and theozone therapeutic device "Bozon$\mathrm{N}^{\prime \prime}$ is used in our study.

\section{Case (A):}

A 65-years-old woman came to our clinic in Aleppo, Syria in 25-12-2018 shows on the right elbow the clinical signs (skin lesions) of cutaneous leishmaniasis (A1), diagnosis is confirmed parasitologically. patient treated with intralesional Glucantime ${ }^{\circledR}$ for eight weeks but that was useless. So, we isolated the infected body part by surrounding it with a bag and introduced oxygen-ozone gas three times per week at concentration $80 \mu \mathrm{g} / \mathrm{ml}$. In 3-1-2019 we decreased the concentration to $60 \mu \mathrm{g} / \mathrm{ml}$ (A2) and in 13-1-2019 we decreased the concentration to $10 \mu \mathrm{g} / \mathrm{ml}$ (A3). In 7-4-2019 we stopped to introduce oxygen-ozone gas (A4) and the case is healed in 11-4-2019 (A5). We used a bag $(80 * 34) \mathrm{cm}$, the exposure to oxygen-ozone gas was 20 minutes after filling the bag. As leaking will occur from the bag it is suggested that this process occurs in a well ventilated area, and after treatment the ozone is sucked from the bag by a vacuum pump so neither the patient, nor the attendant ever breathes in the ozone). The case was regularly monitored after healing until we get the desired result (A6) in 2-7-2019.

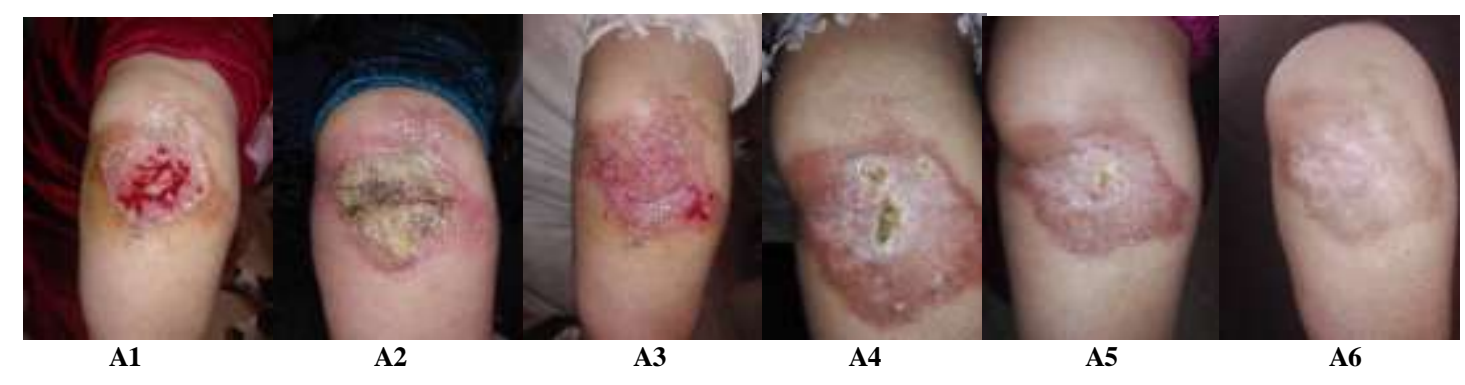


Case (B):

A 53-years-old man came to our clinic in Aleppo, Syria in 2-5-2019 shows on the right wrist the clinical signs (skin lesions) of cutaneous leishmaniasis (B1), diagnosis was confirmed parasitologically. He did not get treatment with Glucantime ${ }^{\circledR}$ or any other medication. We apply the same treatment in case (A) but at constant concentration $80 \mu \mathrm{g} / \mathrm{ml}$ three times a week and by using a bag $(50 * 28) \mathrm{cm}$. The case is healed in $22-6-2019$ where we stopped to introduce oxygen-ozone gas (B2). The case was regularly monitored after healing until we get the desired result (B3) in 10-7-2019.

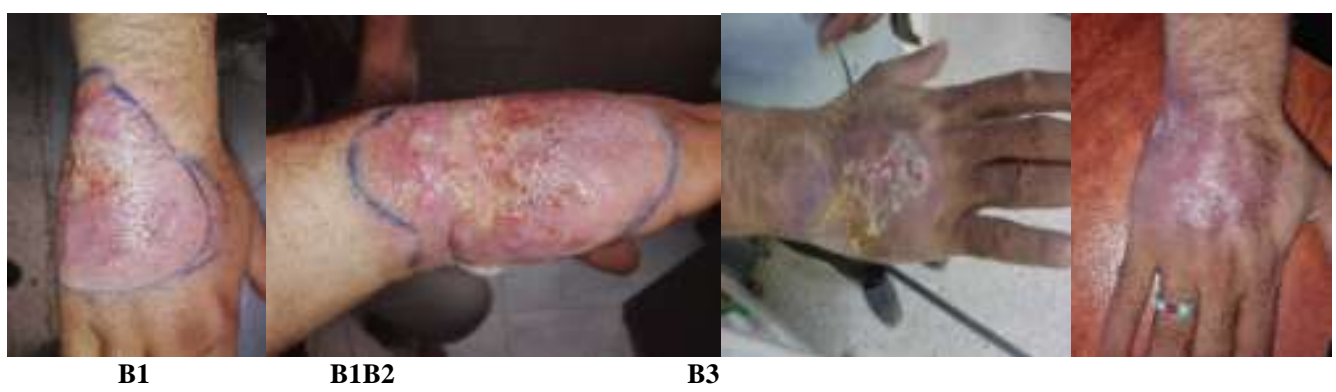

\section{DISCUSSIONS}

Various Studies showed that Ozonated olive oil has in vitro activity against the promastigotes of $L$. major in Iran and this effect is dose dependent where Ozonated olive oil was prepared after production of ozone by bubbling ozone-oxygen gas produced by ozone generator through olive oil until it solidified[14]. Other studies provide clinical evidence which supports and recommends the benefits of ozone therapy in diabetic foot ulcer [15]. Given the above background,we designed our study. This report wants to underline the importance of the ozone therapy in the treatment of Cutaneous Leishmaniasis by "Bagging with ozone" which refers to the method of isolating a body part by surrounding it with a bag (such as hand, arm, leg, foot, but NEVER head), and introducing ozone.No adverse and toxic effects have been pointed out with this therapy.

\section{CONCLUSION}

the efficacy of ozone therapy in the treatment of cutaneous leishmaniasis is appropriate to be evaluated in further clinical studies with a greater number of patientsespecially that case A responded well to ozone thepapy although it showed unresponsiveness to Glucantime ${ }^{\circledR}$ treatment.

\section{ACKNOWLEDGMENT}

Thanks to Mr. Bader Dakkak (exclusive director of the clinic), Mr. NofalNabhan (managing director), Dr.Amal Mohabek (Dermatologist), and nurses Yasmin Hashash\&Najwa Haj Hussin for helping to perform this work.

\section{CONFLICTS OF INTEREST}

Nil.

\section{AUTHORS CONTRIBUTION}

Study conception and design: R. Kello, Diagnosis and Injection oxygen-ozone gas: M.Badawi, Analysis and interpretation of results : R. Kello\&M.Badawi. Both authors reviewed the results and approved the final version of the manuscript.

\section{AUTHORS FUNDING}

Ozone Supportive Therapy Clinic, Aleppo, Syria. 


\section{REFERENCES}

1. Neglected tropical diseases, Cutaneous leishmaniasis factsheet,World Health Organization report.

2. Hayani K, Dandashli A, Weisshaar E. Cutaneous leishmaniasis in Syria: clinical features, current status and the effects of war. Acta DermVenereol. 2015;95:62-6.

3. Jacobson RL. Leishmaniasis in an era of conflict in the Middle East. Vector Borne Zoonotic Dis. 2011;11:247-58.

4. Belazzoug S, Pratlong F, Rioux JA. Un nouveau zymodeme de Leishmania tropica, agent du Bouton d'Alep (Syrie). Archives de l'Institut Pasteur, Algérie, 1988, 56: 9599.

5. Khiami A, Dereure J, Pratlong F, Martini A, Rioux J'A. La leishmaniosecutanehumaine à Leishmania major MON26 aux environs de Damas (Syrie). Bull Soc Exp Pathol 1991; 84: 340-344.

6. Rioux JA, Lanotte G. Leishmania infantum as a cause of cutaneous leishmaniasis. Trans R Soc Trop Med Hyg 1990; 84: 898.

7. Knio KN, Baydoun E, Tawk R, Nuwayri-Salti N. Isoenzyme characterization of Leishmania isolates from Lebanon and Syria. Am J Trop Med Hyg 2000; 63: 43-47.

8. Connolly MA, Heymann DL. Deadly comrades: war and infectious diseases. Lancet. 2002 Dec;360 Suppl:s23-4.

9. Berry I, Berrang-Ford L. Leishmaniasis, war, and political terror: A spatio-temporal analysis. Soc Sci Med 2016; 167: 140-149.

10. Muhjazi, Ghada et al. "Cutaneous leishmaniasis in Syria: A review of available data during the war years: 2011-2018." PLoS neglected tropical diseases vol. 13,12 e0007827.

11. Mohammadzadeh M, Behnaz F, Golshan Z. Efficacy of glucantime for treatment of cutaneous leishmaniasis in Central Iran. J Infect Public Health. 2013;6:120-4.

12. Olliaro PL, Guerin PJ, Gerstl S, Haaskjold AA, Rottingen JA, Sundar S. Treatment options for visceral leishmaniasis:a systematic review of clinical studies done in India,1980-2004. Lancet Infectious Diseases 2005;5:763-74.

13. Firdous R, Yasunzai M, Ranja K. Efficacy of Glucantime in the treatment of old world cutaneous leishmaniasis. International Journal of Dermatology 2009;48:758 62.

14. Rajabi O, Sazgarnia A, Abbasi F, Layegh P. The activity of ozonated olive oil against Leishmania major promastigotes. Iran J Basic Med Sci. 2015;18(9):915-919.

15. Izadi M , Jafari N, Hosseini M, Saafaat O. Therapeutic effects of ozone in patients with diabetic foot ulcers: review of the literature. 2017; 28 (18): 7846-7850. 